\title{
Living Standard of Twelve Selected Somali Regions
}

\section{Mustaf Abdullahi Abdirahman*}

Department of Economics, SIMAD University, Mogadishu, Somalia

\begin{abstract}
In the sense of my paper, the essence of standard of living is the material goods and necessities available to a certain socioeconomic class or a certain geographic area. The study purpose is to find out the standard of living for a panel of twelve selected regions among the eighteen regions in Somalia. The cost of minimum basket (CMB) together with estimated educational fees, high school salary and the exchange rate (ER) from periods of 2009 to 2016 are considered as the study constructs. Random effect model is applied. Cross regional analysis is also employed to check which regions do have higher living standards. The results show a positive and significant relationship between $\mathrm{CMB}$ and high school salary and between ER and CMB. For the cross regional analysis, Mudug, Nugaal and Bari have got higher standard of living compared to the other regions. Lower Juba, Togdheer and middle Shabelle have lower standard of living.
\end{abstract}

Keywords: Cost of minimum basket; Fixed effect model; Standard of living

\section{Introduction}

Standard of living has been measured and looked around centuries. The standard of living included factors such as income, Gross Domestic Product, national economic growth, economic and political stability, environmental quality. It is quite closely related to the quality of live. Standard of living is mostly aimed to compare geographic areas, such as the standard of living of Somali, Kenya and Ethiopia and intra comparison of the Somali regions. The most commonly used measure of standard of living is the Human Development Index. The HDI is based on several factors including, live expectancy at birth, education and income per capita. The HDI was developed by the United Nation as a metric to measure the social and economic development levels of countries.

But in my research paper, I have compared the cost of minimum basket together with estimated education fees and high school salary to find out the standard of living of twelve selected regions among the eighteen regions in Somalia. These regions were selected due to the availability of their data during the study period. High school salary is employed as the income source for the households and the cost of minimum basket, which is the cost of expenditure that consists of the minimum quantities of essential and basic for households (FSNAU), is employed as CMB. Though the CMB does not capture the expenses of school fees, I have estimated the typical household expenditure of education fees for every region. By comparing the CMB to the high school salary, I have obtained the standard of living of each region.

From my knowledge, there have not been studies used this approach to explore the living standard of Somalia; therefore, this study attempts to perform two jobs. First, examine the relationship between $\mathrm{CMB}$, high school salary and exchange rate. Second, compare the cost of minimum basket and high school salary to find which regions do have high salary compared to CMB.

This paper is structured as follows. Section 2 provides an overview literature reflecting living standard. Section 3 describes the method and data used in the empirical analysis. Section 4 discusses the results and interpretation of the empirical model. Finally, section five concentrates on the conclusion.

\section{Literature Review}

According to the economic policy institute of the United States
Intitute [1] there is a link between productivity growth and standard of living. Productivity was measured by labor productivity of goods and service in average, whilst the standard of living was measured by annual inflation adjusted growth from the income side. The study considered period from 1949 through 1999. The results show that labor productivity has grown at about $2.2 \%$. Family income grew at faster rate than productivity from the periods of 1949-1969.

Nube et al. [2] assessed the suitability of body mass index as an indicator of standard of living in developing countries. The data used in the study was generated from Ghana living Standard Survey. The dataset provides information on a wide range of socio-economic variables, at the individual, the household and the community level, including the height and weight data of approximately 9000 adults in the $20 \pm 65$ year age bracket.

Bivariate analysis was used to assess, at the individual level and at the level of population groups, the relationships between adult Body Mass Index and selected household characteristics such as income and expenditure, years of schooling of head of household, access to services, quality of housing, and nutritional status of children. Through multiple regression, indicative estimates have been derived of the effects of these variables on adult BMI.

The results depict that at the individual level, BMI shows a significantly positive relation with the various socio-economic indicators of living standard, though the correlation coefficients indicate a poor fit. However, at the level of population groups, the relationship between BMI and other characteristics of socio-economic development is strong.

Roselyne and Ronald [3] studied household energy consumption versus income and relative standard of living in a panel of seven East Indian Ocean countries. The data employed in their analyses is from the

*Corresponding author: Abdirahman MA, Department of Economics, SIMAD University, Mogadishu, Somalia, Tel: 66112155663; E-mail: musdhafa06@gmail.com

Received November 17, 2017; Accepted January 11, 2018; Published January 18, 2018

Citation: Abdirahman MA (2018) Living Standard of Twelve Selected Somal Regions. Bus Eco J 9: 336. doi: 10.4172/2151-6219.1000336

Copyright: (c) 2018 Abdirahman MA. This is an open-access article distributed under the terms of the Creative Commons Attribution License, which permits unrestricted use, distribution, and reproduction in any medium, provided the original author and source are credited. 
International Energy Agency (IEA), and drawn from the IEA's internet data service. The study employed co-integration technique to find the relationship between income measures and energy consumption measures. This paper differs from these earlier works, as it focuses on whether or not measures of income are adequate for capturing standard of living changes that are the direct, and indirect, result of changes in the level of residential energy usage.

The results show that there is no co-integrating relationship between residential electricity consumption and GDP. As such, income-based measures of standard of living will be incapable of capturing the longrun information content of residential energy consumption as it affects standard of living.

Astorga et al. [4] researched the standard of living in Latin America over the twentieth century. The paper attempts to measure and to some extent explain changes in Latin American living standards over the twentieth century. The authors looked into the long run income trends in Latin America to decide the trends of the living standard through that time.

This paper has made use of a new long run inter-country comparable data set for Latin America to examine the evolution of living standards in the region from 1900 to 2000. The results show that per capita income growth in Latin America is statistically higher and less volatile. In addition, socioeconomic progress was rapid. Furthermore, improvement in Standard of living in Latin American was due to improvement of live expectancy and literacy rate. Finally, there was considerable economic and social convergence between the largest six economies of the region over the century.

Berenger and Verdeir-chouchane [5] studied multidimensional measures of well-being in standard of living and quality of life across countries. These paper two methods of well-being measurement, namely, Totally Fuzzy Analysis and Analysis of Correspondences that take into account liberty, child labor and number of vehicles have been considered. These indices were constructed according to Sen's capability approach. The results of Standard of Living and Quality of live show that African countries have substantial deferencies in many areas except perhaps quality of environment, and highlight the importance of education as a key variable in a country's multidimensional development. Low correlation between QL and GDP per capita gives empirical support to the conceptual distinction.

Ben [6] issued a report discussing the living standard trends in Australia. The author researched Agricare focused on changes in living standard for a broad range of family types in Australia between 2004 to 2014. The report also projects where these living standards will be by 2024 taking into account the current trajectory of Budget policy, expected demographic and socioeconomic change. This research relied on two major sources: changes in disposable income and cost of living index series.

The research finds that standard of living has increased in Australia over the past 10 years however; not all shared that growth evenly. The gap in the living standards between the richest and poorest grew by around 13 percentage points during this period and we project a further widening by 10.4 per cent over the coming decade. Growth in living standards of the top 20 per cent grew by around 22.1 per cent while the bottom 20 per cent grew by just 13.8 per cent.

Hartwell [7] reviewed the rising standard of living of England, 1800-1850. This come with an interest during the industrial revolution of England, particularly the standard living of workers was at poor condition during the first half of the nineteenth century. This paper was prepared by a review in the history of economics. This article finds an upword trend in living standard during the industrial revolution.

Stephen [8] conducted a study on the relationship between real wages and living standard in England. The study looked into several aspects including, the fall in real wages and fall in family income. When it comes to the decrease of real wages, the wages for typical median UK worker fallen by almost $10 \%$ since 2008 . Compared with the trend of $2 \%$ yearly real wage growth (from 1980 to the early 2000s), this represents around a $20 \%$ shortfall. Family income fell by $4 \%$ between 2007-08 and 2012-13

\section{Data, Model and Methodology}

Annual data of high school salary was collected from a sample of two schools in each of the selected twelve regions. Cost of minimum basket and exchange rate are sourced from the Food Security Nutrition Analysis Unit (FSNAU) database (Appendix Table 1). Educational fees included in the $\mathrm{CMB}$ are my own estimates. The adopted regions of the study are Lower Juba, Bay, Middle Shabele, Banadir, Hiraan, Mudug, Nugaal, Bari, Togdheer, W/Galbed and finally Awdal. Dated panel data is employed to explore the relationship between CMB, high school salary and exchange rate. The study period comprises from 2009 to 2016. The detailed description of the data used in the empirical analysis is shown in Appendix Table 2.

For the panel analysis fixed effect model have been employed to decide the kind of relationship that may exist in $\mathrm{CMB}$, high school salary and exchange rate. FEM was adopted because the null hypothesis for the Hausman test was rejected at five percent significance level (Appendix Table 3). Hausman test is used to elucidate which is appropriate, random effect model or fixed effect model. The null hypothesis states random effect model is appropriate. Cross regional analysis based on graph depiction is also used to explore the deference in the living standard a cross regions.

The model of this study is specified as follows: $C M B i t=\alpha+\beta$ it $\mathrm{HSS}+\beta$ it ER $+\mathrm{U}$

CMB is the cost of minimum basket, HSS is the high school salary, ER is the exchange rate, and $U$ is the error term. Subscripts $t$ and I indicate time and cross section.

\section{Results and Interpretation}

Results from the fixed effect model are depicted in Table 1. The analyses show that high school salary and exchange rate has positive and statistically significant relationship with the cost of minimum basket. That means a one percent increase in high school salary will result a 2720.671 increase in the CMB. For the exchange rate, a one percent increase yield 52.71 increase in CMB (Table 1).

Results from the regional comparison are shown in Figure 1. The graph compares the high school salary to the cost of minimum basket. Regions with higher salary compared to $\mathrm{CMB}$ are considered higher living standard whilst, regions with lower salary to $\mathrm{CMB}$ are described as lower living standard. The graph shows periods of 2009 to 2016. As we can see from the graph, Mudug, Nugaal and Bari regions are higher

\begin{tabular}{|l|c|c|c|c|}
\hline Variable & Coefficient & Std. Error & t-Statistic & Prob. \\
\hline ER & 52.71456 & 11.44845 & 4.604516 & 0 \\
\hline HIGH_SC_SALARY & 2720.671 & 978.4823 & 2.7805 & 0.0069 \\
\hline C & 1462825 & 518061.7 & 2.823651 & 0.0061 \\
\hline \multicolumn{4}{|c|}{ Table 1: Estimation of model parameters. } \\
\hline
\end{tabular}




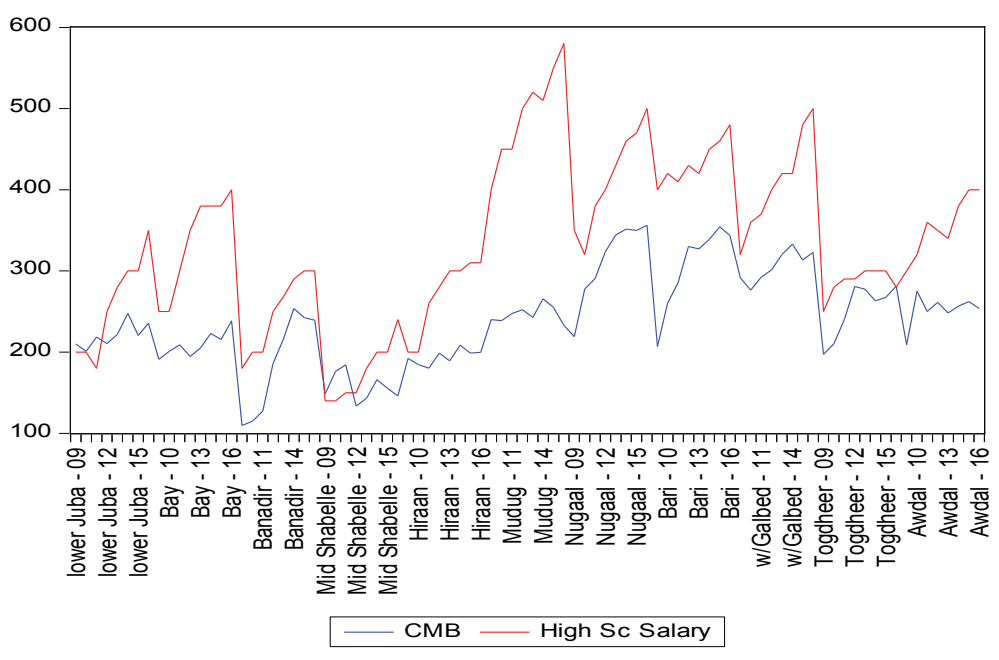

Figure 1: Regional comparison of CMB and HSS 2009-2016.

in salary compared to CMB. Lower Juba, Middle Shable and Togdheer are lower in Salary compared to CMB.

\section{Conclusion}

The study investigated the relationship between cost of minimum basket with estimated school fees, high school salary and exchange rate for twelve-selected regions among the eighteen regions of Somalia during 2009 to 2016 . The study also assessed the living standard of the selected regions by comparing the CMB and high school salary. The study used panel data for the regression analysis and intra analysis between regions. The results from the regression demonstrate that High school Salary and Exchange rate have positive and significant relationship to CMB. For the intra analysis of the regions, Mudug, Nugaal and Bari have higher standard of living among the regions in discussion while, Lower Juba, Middle Shabele and Togdheer have lower standard of living.

\section{References}

1. Intitute $P(2005)$ The link between productivity growth and living standard. Economic policy institute.
2. Nube M, Asenso-Okyere WK, van den Boom GJM (1988) Body mass index as indicator of standard of living in developing countries. European Journal of Clinical Nutrition 52: 136-144.

3. Roselyne J, Ronald DR (2010) Household Energy Consumption Versus Income And Relative Standard of Living: A Panel Approach. Energy Policy 35: 50-60.

4. Astorga P, Berges AR, Fitzgerald V (2005) The Standard of Living In Latin America Over The Twentieth Century. The Economic History Review 58: 765796.

5. Bérenger V Verdier-Chouchane A (2007) Multidimensional Measures of Well-Being: Standard of Living and Quality of Life Across Countries. World Development 35: 1259-1276.

6. Ben P (2015) Living Standard Trends in Australia: Report for Anglicare Australia. Nastem: University Of Canberra.

7. Hartwell RM (1961) The rising standard of living in England, 1800-1850. The Economic History Review.

8. Stephen M (2015) Real wages and living standards. Centre for economic performance. 